\title{
Pseudotumor Cerebri : A Rare Presentation of Systemic Lupus Erythematosus
}

\author{
ADAS $^{\mathrm{a}}$, JC DAS ${ }^{\mathrm{b}}$, AAAHMAD ${ }^{\mathrm{c}}$, MAKAHHAR $^{\mathrm{d}}$
}

\begin{abstract}
Summary:
Raised intracranial pressure in the absence of an intracranial mass or hydrocephalus (BIH or pseudotumor cerebri) has been described in association with many conditions including SLE. Several pathogenic pathways tie BIH with SLE as thrombotic obliteration of cerebral arteriolar and venous systems and immune complex deposition within the arachnoid villi that are responsible for cerebrospinal fluid (CSF)
\end{abstract}

\section{Introduction:}

Systemic lupus erythematosus (SLE) is a multisystem autoimmune disease characterized by diverse manifestations encompassing almost all organ systems and the finding of antibodies in the blood directed against one or more components of cell nuclei ${ }^{1}$.Neuropsychiatric manifestations can occur in up to two-thirds of patients with $\mathrm{SLE}^{2}$. Pseudotumour cerebri (PTC) is an exceedingly rare manifestation of neuropsychiatric lupus and one of the causes of headache in SLE patients ${ }^{2}$. It is characterized by an elevated intracranial pressure (papilloedema with occasional abducent nerve palsy) in the absence of space occupying lesion or ventricular enlargement, biochemical and cytological abnormalities, in alert and oriented patients ${ }^{3,4}$. Pseudotumour cerebri (PTC) may present as unremitting headache ${ }^{3}$. If this condition is not treated promptly it can even lead to blindness. Since the first case of Bettman et al ${ }^{5}$, there have been sporadic reports of concomitant SLE and PTC in adults. Here, we describe a case of 22-year-old lady presenting with prolonged fever and headache as the main features of

a. Dr. Aparna Das, Asso. Prof.Dept. of Medicine, Dhaka Medical College

b. Dr. Jiban Chandra Das, IMO, Dept. of Medicine, Dhaka Medical College

c. Dr. Abdullah Al Ahmad, HMO, Dept. of Medicine, Dhaka Medical College

d. Prof. Md Azizul Kahhar, Professor. Dept. of Medicine, Dhaka Medical College

Address of Correspondence: Dr. Aparna Das, Asso. Prof., Dept. of Medicine, Dhaka Medical College.

Received: 30 September, 2014 Accepted: 20 December, 2015 absorption. The diagnosis of BIH was confirmed by increased intracranial pressure in the absence of any abnormal radiological findings of the brain. We report a young woman with SLE complicated by BIH which resolved with corticosteroid therapy and osmotic diuretics.

Key wards: Pseudotumour cerebri, Systemic lupus erythematosus

(J Bangladesh Coll Phys Surg 2016; 34: 104-107)

her disease who showed a dramatic response to oral steroids.

\section{Case Report:}

A 22-year-old lady presented with 1-year and 6-months duration of low-grade fever, headache, episodic joint pain and hair fall. She lost $8 \mathrm{~kg}$ of her body weight over the course of her illness and developed an ulcer in oral cavity 5 days prior to admission at our hospital. Her headache was unilateral, throbbing, predominantly occurring on awaking from sleep without other aggravating and relieving factors. Apart from malaise, nausea and occasional dizziness on standing, she denies any vomiting, blurring of vision, diplopia, reduction in urinary volume, alteration of consciousness. Review of other systems was negative other than the above mentioned symptoms. She had an unremarkable past medical and family history. She does not smoke, drink alcohol and have never used intravenous drugs.

With these complaints she had visited two physicians 1-year back and had been admitted once at a tertiary level hospital one month ago where she was diagnosed with urinary tract infection and was given some insight about the possibility of SLE. Having been not cured of fever she got admitted at a secondary hospital where her fever was attributed to urinary tract infection. Her medication included occasional use of paracetamol, naproxen sodium for headache, oral cefuroxime, intravenous levofloxacin for urinary tract infection and had been transfused with 2 units of fresh human whole blood. She denies taking any other medications including oral contraceptives. On admission, examination revealed a thin, ill-looking young woman with a temperature of 


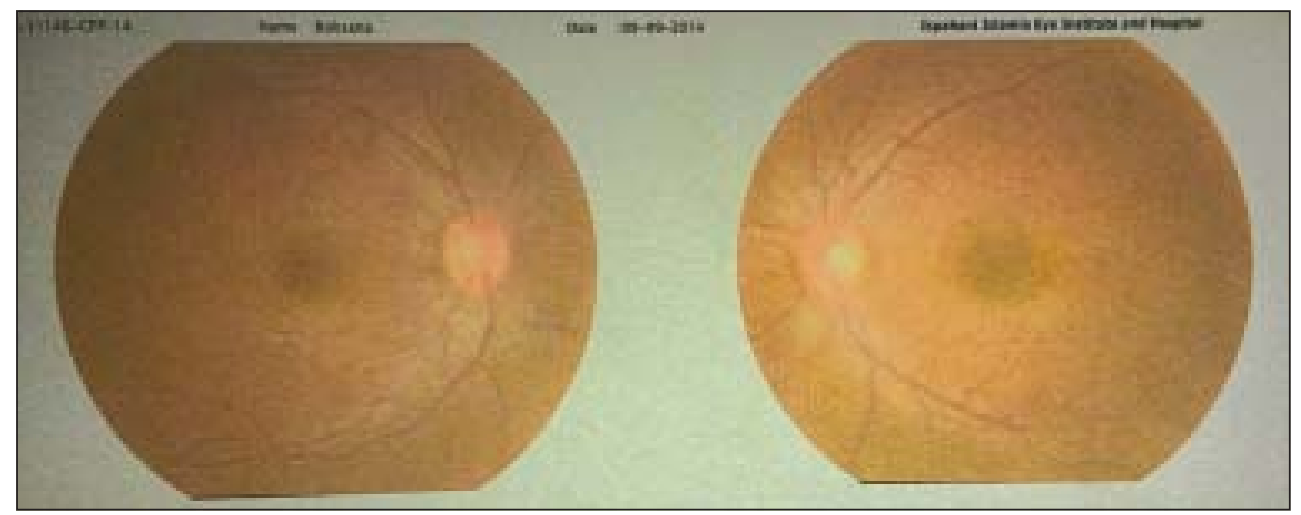

Fig.-1: Fundus photography of both Eye (Bilateral papiloedema)

38.5 degree C, blood pressure of 120/70 mm of $\mathrm{Hg}$ and body weight of $40 \mathrm{~kg}$. She had an erythematous ulcer on hard palate, mild divergent squint on left eye. Fundoscopy revealed bilateral gross papilloedema with normal visual acuity and papillary reflexes. Rest of the neurological examination was normal.

Routine laboratory work-up revealed normocytic normochromic anaemia with a haematocrit of $60 \%$. White blood cells were $8000 / \mathrm{cu}$ mm with $85 \%$ of WBC being segmented neutrophil.ESR was raised at $36 \mathrm{~mm}$ in first

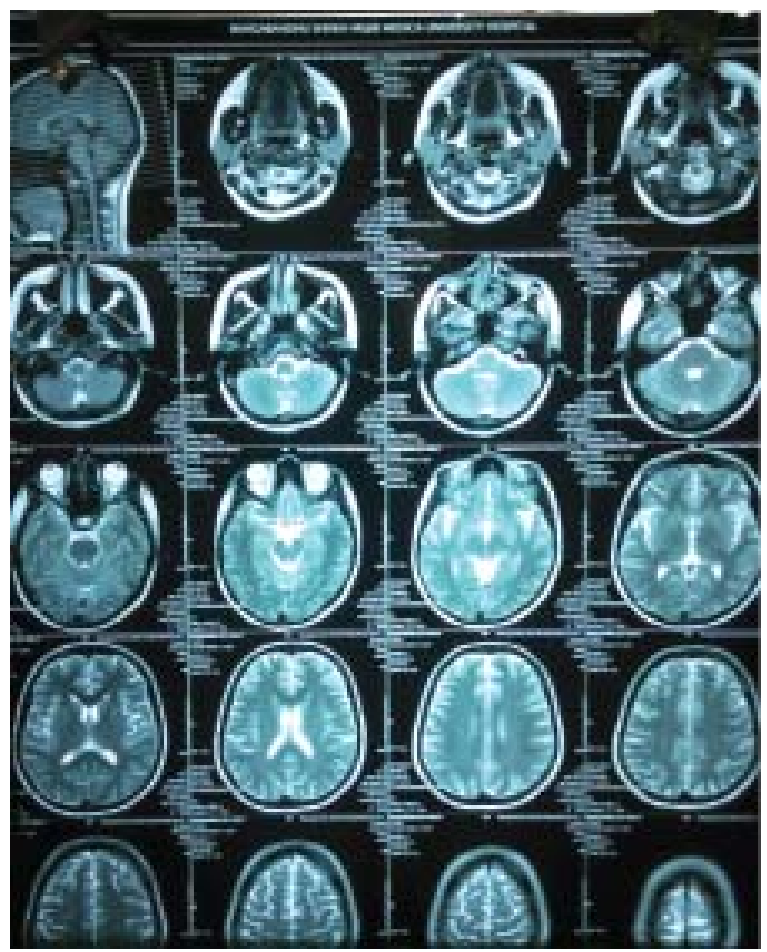

Fig.-2: MRI of brain- unremarkable hour. Urine microscopy showed presence of RBC (2030/HPF), WBC (2-5/HPF), but no casts and albumin. Urine culture revealed growth of no organisms. However, 24-hour urinary total protein estimation showed proteinuria at $0.5 \mathrm{gm} /$ day .Her serum creatinine was $1.1 \mathrm{mg} / \mathrm{dl}$ and serum electrolytes were normal with sodium being $140 \mathrm{mmol} / \mathrm{L}$, potassium $3.9 \mathrm{mmol} / \mathrm{L}$, chloride $109 \mathrm{mmol} / \mathrm{L}$. Ultrasonography of whole abdomen was normal except tiny nebothian cyst in cervix.

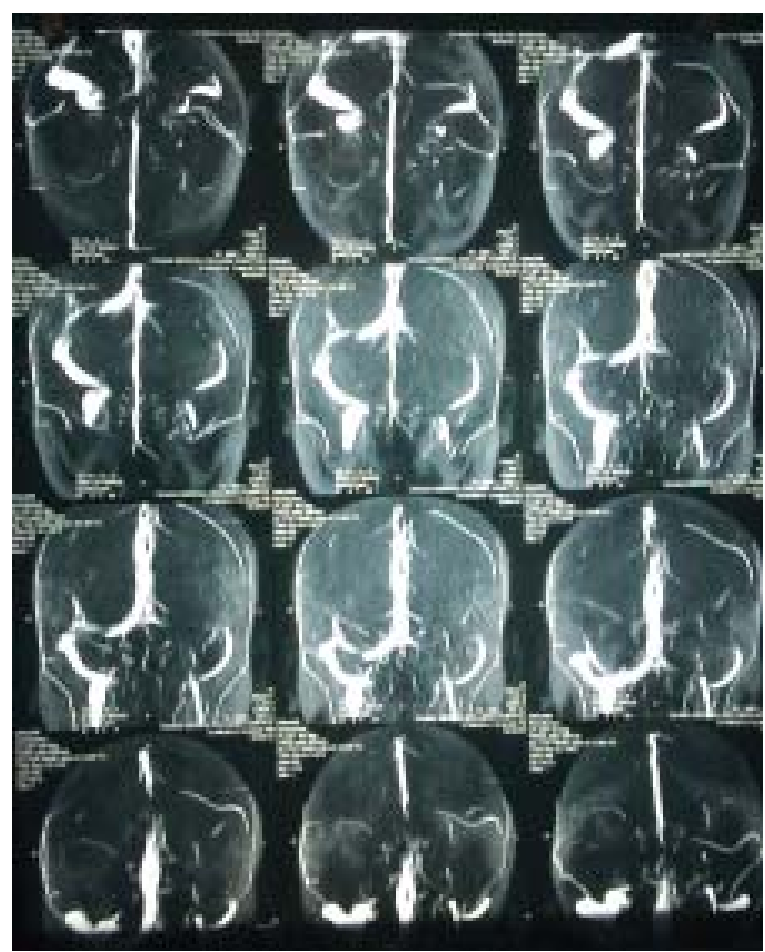

Fig.-3: MRV of brain and neck vessels- Normal 
Further work-up revealed highly positive anti-nuclear antibodies (ANA), with a titre at $37 \mathrm{U} / \mathrm{ml}$, with coarse speckled; anti double-stranded DNA (ds-DNA) with titre at $136.7 \mathrm{U} / \mathrm{ml}($ normal $<2 \mathrm{U} / \mathrm{ml})$.Serum $\mathrm{C} 3$ and $\mathrm{C} 4$ were reduced at $0.286 \mathrm{~g} / \mathrm{L}$ and $0.087 \mathrm{~g} / \mathrm{L}$ respectively. Antiphospholipid antibody was negative.Rheumatoid factor was negative. Neuro-imaging of brain with MRI showed no abnormality and magnetic resonance venography (MRV) was normal with no evidence of cerebral venous sinus thrombosis. Subsequently, a lumber puncture revealed an opening pressure of $42 \mathrm{~cm}$ of $\mathrm{H} 2 \mathrm{O}$ with a normal haemato-cytological and chemical composition with WBC being 02/cu mm, plenty of RBC, protein concentration of $3 \mathrm{mg} / \mathrm{dl}$ and glucose level at $2.8 \mathrm{mmol} / \mathrm{L}$ and it was negative on Gram and Z-N staining.

\section{Discussion:}

According to the revised American College of Rheumatology (ACR) criteria ${ }^{6}$ our patient was diagnosed with SLE with her oral ulceration, history of episodic joint pain, positive result for ANA and anti dsDNA, microscopic haematuria (detected on RME) and proteinuria (detected on 24-hour urinary total protein estimation).

Headache is a common symptom in SLE patients. Different types of headache may occur in SLE due to various underlying conditions. Pseudotumour cerebri (PTC) is a rare manifestation of neuropsychiatric SLE but commonly presents with headache. Early detection and treatment is important since it can lead to permanent visual impairment ranging from 6 to $24 \%$ of cases ${ }^{7}$ (Data varies among different studies).

This patient fulfilled the modified Dandy criteria ${ }^{4}$ for the diagnosis of Pseudotumour cerebri (PTC) with signs of raised intracranial pressure (headache, bilateral papilloedema); no localized findings on neurological examination; normal neuro-diagnostic studies(brain MRI and MR venography) with no evidence of venous obstructive disease; raised intracranial pressure measured by lumber puncture (42 cm H2O); normal chemical and cytological composition of CSF; and no abnormality in consciousness leve l(alert and awake patient). Certain drugs (vitamin A, tetracyclines, nalidixic acid, nitrofurantoin, sulpha derivatives, lithium, phenytoin, indomethacin, oral contraceptive pills, and steroids), endocrinological abnormalities (hypo- and hyperthyroidism, hypoparathyroidism, adrenal insuffiency, Cushing's syndrome) and hypertension are known causes of Pseudotumour cerebri. She was not on above mentioned antibiotics and vitamins and did not use oral contraceptive pills. Our patient did not have any endocrinopathies.. She has never had hypertension (we also found normal blood pressure since admission at our hospital). Corticosteroid therapy could not be implicated because she was not receiving prednisolone at the time of diagnosis of Pseudotumour cerebri. Therefore, we had to think of SLE as the cause of PTC in our patient.

However, the association of SLE and intracranial hypertension is still unclear. The proposed mechanisms include immune-mediated injury within the arachnoid villi and consequent reduction in CSF absorption or probable hypercoagulable state without overt vascular thrombosis giving rise to micro-obliteration of cerebral arteriolar and venous systems ${ }^{8,9,10}$. Young females with serologically active lupus, severe form renal lesions, past history of arterial or venous thrombosis, and laboratory evidence of procoagulant activity appears to be at increased risk of raised intracranial pressure ${ }^{11}$. Our patient had mild renal disease (RBC 20-30/HPF, 24hour urinary total protein $0.5 \mathrm{gm} /$ day, no casts). She had no past history of thrombosis. The antiphospholipid antibody (Ig M and Ig G) work-up was also negative. Therefore, Pseudotumour cerebri in this patient was considered as a manifestation of neuropsychiatric SLE. Our patient, similar to other patients with SLEassociated pseudotumour cerebri ${ }^{8}$, responded dramatically to steroids (40 $\mathrm{mg}$ of oral prednisolone) with remission from her headache, resolution of bilateral papilloedema, which is quite atypical for idiopathic intracranial hypertension.

\section{Conclusion:}

In conclusion, we described a woman with SLE who presented to us with fever and headache. Headache is a common symptom in patients with neuropsychiatric SLE. Sometimes it can be the only presenting symptom. Therefore, Pseudotumour cerebri should be considered in the differential diagnosis of headache in patients with SLE, and work-up of Pseudotumour cerebri should include screening for connective tissue diseases.

\section{References:}

1. Mills JA. Systemic lupus erythematosus. New England Journal of Medicine 1994; 330: 1871-9 
2. Guwani Liyanage,H M D Herath.Pseudo tumour cerebri in systemic lupus erythemaosus.Srilanka Journal of Child Health 2008;37:59-60

3. Kesler A, Fattal-Valevski A. Idiopathic intracranial hypertension in the pediatric population. J Child Neurol 2002; 17: 745-748.

4. Wall M. Idiopathic intracranial hypertension. Neurol Clin 1991; 9: 73-95.

5. Bettman JW, Daroff RB, Sanders MD, Joyt WF. Papilledema and asymptomatic intracranial hypertension in systemic lupus erythematosus. A fluoresceinangiographic study of resolving papilloedema. Arch Ophthalmol 1968;80:189-93.

6. Tan EM, Cohen AS, Fries JF, et al. The 1982 revised criteria for the classification of systemic lupus erythematosus. Arthritis Rheum 1982; 25: 1271-1277.
7. Biousse V,Bruce BB, Newman NJ .Update on the pathophysiology and management of idiopathic intracranial hypertension. J Neurol Neurosurg Psychiatry. 2012;83(5):488-94. doi: 10.1136/jnnp-2011-302029

8. Green L, Vinker S, Amital H, Amir T, Bar-Dayan Y, Levi $\mathrm{Y}$, et al. Pseudotumor cerebri in systemic lupus erythematosus. Semin Arthritis Rheum 1995;25:103-8.

9. Horoshovski D, Amital H, Katz M, Shoenfeld Y.Pseudotumor cerebri in SLE. Clin Rheumatol 1995;14:708-10.

10. Parnass SM, Goodwin JA, Patel DV, Levinson DJ, Reinhard JD. Dural sinus thrombosis: A mechanism for pseudotumor cerebri in systemic lupus erythematosus. J Rheumatol 1987;14:152-5.

11. Nampoory MR, Johny KV, Gupta RK, Constandi JN, Nair MP, al-Muzeiri I. Treatable intracranial hypertension in patients with lupus nephritis. Lupus 1997;6:597-602. 